\title{
Outcome, Economic and Operational Benefits of Hybrid Courses - A Public Research University Perspective
}

\section{Dr. David J. Dimas, The University of California, Irvine}

Dr. Dimas has over 25 years of experience which centers on consulting in simulation and design and developing and teaching a curriculum of related engineering analysis and product development courses in both commercial and academic settings. He served in a number of top-level management positions at both PDA Engineering and MSC Software including director of training services, customer support, educational sales and product documentation in the computer aided engineering (CAE) market space. At MSC Software he pioneered new techniques and guided the development of two highly successful interactive DVD based courses in the application of finite element analysis (FEA) in product development. He also developed a unique, low-cost, flexible method to produce and maintain DVD versions of a curriculum of 15 courses related to CAE. Both provided increased knowledge access, transfer and retention. His industrial background also focused on applying theoretical aspects of numerical methods in simulation and design to wide variety of product development issues. He has served on the faculty at UC Irvine since 1986 and has brought these practical applications into the classroom, providing students with significant improvements in their ability to learn the theory and "art" of engineering simulation and design. He received his B.S. and M.S. in Mechanical Engineering and Ph.D. in Civil Engineering all from UC Irvine.

Faryar Jabbari, University of California, Irvine

Dr. Jia Frydenberg, University of California, Irvine

Dr. Frydenberg is the Emeritus Associate Dean of Distance Learning at the University of California, Irvine. 


\title{
Outcome, Economic and Operational Benefits of Hybrid Courses: A Public Research University Perspective
}

\begin{abstract}
This paper describes an experiment at the University of California, Irvine (UCI) that uses a combination of technology and pedagogical approaches to improve learning outcomes for engineering students while reducing course delivery costs. Like most public research universities, UCI faces the challenge of improving learning outcomes in the face of declining State and Federal funding. This challenge has many elements; 1) As class sizes increase, student participation is hindered and class enrollments often exceed classroom capacities; 2) A lack of immediate feedback on student learning hinders timely interventions that would otherwise help students succeed; 3) Operation of classes is burdened by administrative details that ineffectively absorb a large percentage of the available Faculty and Teaching Assistant resources; 4) Class time spent on course topics is often not proportional to the level of difficulty of the material or mapped to the non-uniform needs of the students; 5) Students have little control over the pace of learning; 6) Research-oriented faculty do not have the time or motivation required to investigate and adopt new learning technologies and methods; 7) Faculty frequently distrust unproven or unfamiliar technologies or teaching methods.

To address these issues, three courses in the Department of Mechanical and Aerospace Engineering at a major U.S. research university were modified to include the expanded use of instructional technologies and new pedagogical practices. This included the expanded use of asynchronous online content such as video lectures, prompted and graded discussion forums, frequent quizzes and "just-in-time" reference materials and links. A key component was the use of an assessment tool aimed at providing timely feedback. These tools allowed both students and instructors to measure learning achievements in the previous week of the course and then modify the subsequent week's lectures and attendance accordingly. The courses varied in size (between 50 and 320), content area (dynamics, vibrations, and finite element analysis) and level (sophomore, junior and senior.) Courses were monitored over a two year period during which the three faculty involved met frequently with each other and with the supporting instructional design and distance learning delivery teams. The results show measurable improvements in student satisfaction, course outcomes, and operational efficiency while defining clear and convincing paths to motivate additional faculty to adopt all or some of pedagogy and online learning modalities.
\end{abstract}


Financial Pressure

According to the Science and Engineering Indicators 2012 report by the National Science Foundation, State funds for the top 100 public research universities in the United States dropped 10 percent between 2002 and 2010. During the same period enrollments increased 12 percent, dropping the per-student State funding nearly $20 \%$ from $\$ 10,195$ to $\$ 8,157$. States with the worst economic conditions (e.g., California, Michigan, Florida) suffered even more dramatic drops in state funding. Exacerbated by the 2008-2012 recession, federal funding for students and research activities has also decreased during this same period. Responding to a need to maintain the global competitiveness of the U.S. workforce, President Obama has stated his intent to help reduce the rate of tuition increases at U.S. colleges and universities by $50 \%$ over the next decade. This increase in the number of students and decrease in state and federal support have and will continue to put significant pressure on administrators and faculty at public research universities to come up with creative ways to continue to provide high quality education to more students with fewer resources.

\section{Terminology}

The field of online and blended educational practices is still so new that terminology and nomenclature have not yet solidified. In this study and this paper, the term "hybrid" or "blended" is used to describe courses where the full amount of instruction in the classroom was augmented by multiple technical and procedural innovations. This type of course is often elsewhere termed "web-assisted," was not used since the introduction and evaluation of the online work of both students and instructors in this study have led to a situation where it is indeed feasible for the university to decrease the classroom time and replace that with online activities. The latter is the kind generally called "hybrid," and was a better fit to the actual situation studied.

\section{Faculty Perspective}

At most colleges and universities promotions and tenure are a function of research, publications, teaching and service. In a study of tenure and merit pay, Kasten reports that "teaching is second in importance to research" and that "adequate teaching is a necessary but not sufficient condition for tenure." ${ }^{1}$ Teaching is a key job requirement and indeed many faculty report that this interaction with students is one of the reasons they chose an academic career. However, as junior faculty often lament - the realities of supporting the many aspects of research and the strong relationship between success in these areas and success in their academic careers cause them to keep all activities that support research as top priorities.

It is also important to note that the pace of research changes rapidly and requires much more energy to sustain than the teaching and service related components of the profession. In contrast, instructional methods and methodologies have remained fairly constant over the last 20 to 30 
years, with only minor adoptions of instructional technologies to aid teaching. Only in the last 10 years or so, a variety of significant technologies have become available and sufficiently ubiquitous to prompt large scale interest in alternative means of delivery.

Taking the time to learn the strategy and tools required to create and deliver a successful hybrid course at any level of sophistication often detracts from "...other professional activities which may be needed to be successful in the tenure process." Also, most research universities do not allow any "workload release" for the additional effort often required for the initial development of a hybrid course. Faculty are used to being the "experts" and due to the lack of priority and/or time are not properly motivated to become experts in the development and delivery of effective hybrid courses. They further cite the "complexity" of developing effective online courses including technical, pedagogical, and administrative (no time or budget, lack of training and no clear direction from management ) efforts as well as the risk of degrading the quality of instruction and hence potential damage to the institutional reputation as reasons not to engage in the hybridization of their classes. ${ }^{2}$

Also contributing to their reluctance to develop blended courses, more experienced faculty often have had previous experience with technologies that failed to live up to promises of measurable improvements in teaching effectiveness and efficiencies (e.g., video-taped courses, computer assisted training and podcasts). Faculty often distrust new methods until proven effective. Further compounding this issue, multiple levels of academic administration rarely align with respect to the vision for the incorporation of online content into graduate and undergraduate courses. A combination of the factors led one researcher to the same conclusion "... faculty are often discouraged from teaching blended courses."

\section{Current Practice}

Online and hybrid education has been studied extensively with particular scrutiny in the past 10 years. A consistent thread within the more recent literature is that hybrid course design combining face-to-face instruction with a variety of online instructional modalities increased or at a minimum maintained the attainment of the desired learning outcome when compared to either $100 \%$ face-to-face or $100 \%$ online courses. ${ }^{5,6,7,13}$ These instructional modalities included "low stakes" evaluations ${ }^{12}$, recorded lectures ${ }^{4}$, online quizzes ${ }^{1}$, and other online course components. Some researchers even extend these results beyond hybrid classes. A team lead by Tallent-Runnels ${ }^{9}$ summarized their investigations with "...overwhelming evidence has shown that learning in an online environment can be as effective as a traditional classroom."

Recent experiments with Massively Online Open Courses (MOOCs) have spawned intensive interest and debate at many levels of academia and business. The data from some of the early MOOCs supports similar conclusions that online content (in this case $100 \%$ online) can be perceived as good as or better than live classes. Professor Anant Agarwal, a researcher in computer architecture at MIT, who now serves as the president of edX (a MOOC-related joint 
venture between Harvard and MIT) received strong, positive feedback from one of the initial MOOCs in electric circuits. The course, which attracted a large number (70\%) of degreed students, was rated better than the live version of the class by $63 \%$ of the participants. Another $36 \%$ rated the class comparable to the live version and only $1 \%$ said the class was worse. While this type of success is heavily dependent on the quality of the instructor, self-selection of those who take the class, material, course design and interaction between the students, it and the many other related examples of the success of MOOCs and the intense interest from the business community serves to further underscore the possibilities of success in moving to more hybridized courses in engineering education.

Another key theme from the recent literature is that students perform better when they have more control of the learning ${ }^{2}$. This control includes being able to modify (1) the pace of the learning including stopping, slowing down or repeating a pre-recorded lecture (2) the method of learning including choosing to watch live vs. online lectures or live vs. online discussions and (3) the amount of instruction, for example, choosing to watch the pre-recorded lecture and attend the live lecture and (4) being able to regularly provide feedback to the instructor regarding the class. Some assessment of the value of student "control" in a course was performed as a part of this study and is included below.

\section{The Hybrid Course Maturity Model}

Effective online courses include a range of components that improve quality and operational efficiency of the design and delivery of courses. Faculty often begin their path toward course hybridization with a simple course website that includes components such as the course syllabus, readings, assignments, online links, schedules and processes that allow instructors to communicate changes in schedule, assignments and related information to the class.

The next steps often include the addition of processes within the course website to upload homework. This can lead to significant time savings for both faculty and teaching assistants as discussed further below while making it much easier to abide by FERPA (Family Educational Rights and Privacy Act).

Low stakes polls and quizzes and other components designed to develop a "feedback loop" are often a next logical step. Polls designed to assess which topics and related homework assignments that are the least well understood by the class are fairly easy to implement in most Learning Management Systems (LMS) such as Moodle and Blackboard. Most faculty are skilled at creating tests designed to assess a student's mastery of a group of concepts covered in lecture and reinforced via homework. Designing a few short-answer poll questions to assess the "muddiest points" from the preceding week's lectures can be a bit more challenging but as with many aspects of the "art" of engineering, this task can be mastered with experience and guidance from other faculty and staff experienced in instructional design. This feedback loop concept is discussed further in the next section. 
Simple course website data, student communication tools, homework uploading, and polls are fairly easy for most faculty to understand and implement in most LMS systems, however, further maturation along the continuum of course hybridization requires more commitment and time to learn both the pedagogy and tools. While creating a variety of true-false, multiple choice, and short answer quizzes do take more effort and skill, they usually yield significant long term benefits since they are much easier to grade (often completely automated) which can save significant time especially in large classes. Quizzes take a bit more understanding and "programming" especially if quiz questions for specific instances of a quiz are selected from a "bank" of quiz questions. The key benefit of polls and quizzes is the "just-in-time" assessments of the preceding week's lectures that yield information that the instructor can use to modify his or her lectures or discussion section the following week. The perceived extra work understanding the technology and pedagogy of course components such as quizzes often causes faculty to underutilize these options. Those who have taken the time to implement them clearly see the value of such tools in improving the quality of the courses and the efficient operation of future courses. Quizzes are especially valuable in this respect since most are automatically graded.

Most faculty have had some experience recording their lectures in one form or another. Since staff or funding required to professionally videotape a live lecture are often not available, these recordings are usually created using a single, often low quality, video or document camera. Recordings are then posted to a website for student access. The issue with most recordings is the quality is so low that they are difficult to watch. Unless the faculty use a good quality microphone, the audio can cut out or be muddy, especially if a lapel microphone is not used. Video quality can also suffer if a single camera is used and there is no camera operator to zoom in and out appropriately during the lecture. Classroom lighting can also be a challenge. Document cameras can be useful but instructors often have to use a wider than normal pen to allow the camera to resolve the writing. This presents difficulties for many engineering courses due to the intricate nature of many of the equations and drawings. There are a variety of alternatives to live lecture capture that can be effective for hybrid classes. A common technique is to use screen recording software such as Camtasia. In this study, faculty used three methods to create content that was subsequently captured adding both audio and video annotations with Camtasia. In order of difficulty from least to most, these are (1) document camera used in the instructors' office, (2) handwritten text, equations and drawings that were digitally captured via tablet computers and a stylus and (3) digitally typeset and drawn materials using text, drawing, and equation creation tools in PowerPoint.

In some hybrid courses, prerecorded lectures are used in place of live lectures for a few days or sometimes a full week of the course duration. A common technique during those weeks or days when a live lecture does not occur is to have a virtual discussion forum to encourage discussion of the week's content. The instructor will give a "prompt" for the discussion requiring students to post a few paragraphs of "response" to the prompt and often also requiring students to post short (usually something longer than a 140 character tweet, but no more than a few sentences) 
comments to the responses of 2-3 other students. The instructor typically will not respond to every posting in the forum but will interject and guide the discussions. The online forums can also be valuable even if live lectures continuously occur.

To augment the posted version of worked-out homework assignments some faculty and/or TA's have used some of the recoding techniques discussed above to capture a step-by-step solution to homework assignments. Other techniques that are often essential for engineering courses with a significant amount of design and team project work include subsections of the course shell that provide access-controlled, group project collaboration and presentation functions.

\section{Study Design}

In this study three face-to-face courses in the Department of Mechanical and Aerospace Engineering with varying levels of additional online content were assessed over a three year period beginning in the winter quarter of 2011 and ending in the winter of 2013. Each course is 10 weeks in length and each carries 4 units or credit. The courses meet from between 3-4 hours of lecture per week and each requires students to attend at least one 1-hour discussion per week usually taught by graduate student teaching assistants. The courses varied in size between 50 and 350 .

The courses in this study include one lower division required class and two upper division elective courses. The lower division class is Dynamics which is a required class in the Civil, Mechanical and Aerospace engineering undergraduate degree programs. Since this course is lower division and is required in three degree programs within the school of engineering, the course typically has very high enrollments (300-350) and often fills up due to a lack of available seats in the physical classroom. The course covers kinetics and dynamics of particles and rigid bodies using Newton-Euler, Work/Energy, and Impulse/Momentum methods. The second course in the study is Vibrations which is an elective course in both Mechanical and Aerospace Engineering. This course covers single- and multi-degree of freedom systems, free and forced vibrations, Fourier series, convolution integral, mass/stiffness matrices, and normal modes and also includes a design project. The course is 4.0 units including 1.0 unit of design. The third course in the study is Introduction to Computer-Aided Engineering. This course covers the theory and application of the finite element method to practical design issues. The course is also 4.0 units and includes 2.0 design units. All three courses in this study required weekly submission of homework. With the exception of the 2011 version of the Vibrations class, the same instructor taught each class for the three year period of the study. The courses are summarized in the table below:

\section{Table 1}

Courses in this Study 


\begin{tabular}{|c|c|c|c|c|c|}
\hline Course Title & Level & Units & $\begin{array}{c}\text { Design } \\
\text { Units }\end{array}$ & Status & $\begin{array}{c}\text { Enrollment } \\
\text { Range }\end{array}$ \\
\hline Dynamics & Soph. & 4.0 & 0.0 & Required & $314-352$ \\
\hline $\begin{array}{c}\text { Computer- } \\
\text { Aided } \\
\text { Engineering }\end{array}$ & $\begin{array}{c}\text { Jr.- } \\
\text { Sr. }\end{array}$ & 4.0 & 2.0 & Elective & $47-80$ \\
\hline Vibrations & $\begin{array}{c}\text { Jr.- } \\
\text { Sr. }\end{array}$ & 4.0 & 1.0 & Elective & $45-50$ \\
\hline
\end{tabular}

At the end of each course, the University's standard course evaluation form is used to assess the students' qualitative rating of the instructor, the course, and the course outcomes. This evaluation includes 17 questions. A majority (13) of these questions are intended to rate the instructor using a A-F grading scale and the others rate the textbook, amount of academic dishonesty, the students' estimate of their current grade and the difficulty of the class. Students can also provide specific written feedback via this survey as well.

In the Dynamics class and in the Introduction to Computer Aided Engineering class additional class surveys are conducted to specifically assess the use of various online components of the classes. This survey is integrated into the online course shell as a required but "low stakes" assignment. The survey consists of multiple choice questions aimed at assessing the value of the pre-recorded lectures and video versions of worked-out homework assignments available from the online course shell. The details of the questions are included in the result section of this paper.

The first year of the study (2011) is considered a baseline in which no major modifications to the courses occurred. During the second and third year increasing amounts of online content and feedback mechanisms were implemented. Course modifications included the expanded use of asynchronous online content such as:

- Pre-recorded video lectures

- Online homework submission and grading

- Frequent short, "low stakes" quizzes

- Muddiest point "polls"

- Prompted and graded discussion forums

- Posted homework's solutions (both written and video-based)

- Chat areas for student-teacher and student-student interactions

- "just-in-time" reference materials and links

- Group project collaboration and presentation functions 
- Related video, online links and posted documents

Two key focal areas of this study are "control" and "feedback": students having control over the speed and repetition they feel they need for a given lecture or a segment of a lecture (via the prerecorded lecture content available from the course shell); the instructor having control over students' commitment to "read/watch" the material before the key meeting (formerly lecture). Student activity is monitored via "activity reports" in the online learning management systems (Moodle). The feedback concept is also a two-way interaction: the instructor being able to evaluate the comprehension of students in near real time to make adjustments, students seeing their overall comprehension compared to their peers (by viewing overall statistics), and seeing the conceptual questions (in the form of "low stakes" quizzes) that highlight the key points from the point of view of the instructor. Together these tools allowed both students and instructors to measure the learning achievements in the previous week of the course. The instructor could then modify the subsequent week's lectures and the students were able to reallocate their resources (time) as needed. With the availability of online lectures and other hybrid course activities students are also able to best match their needs and learning styles to the available learning tools. The asynchronous nature of these resources also allows students to absorb the learning at times that are most conducive to their schedule and where / when their ability to learn is at a high level. Several questions in this study focused on the students' assessment of the value of both "student control" and the "flexibility" of the course to adapt to different needs and learning styles of the students.

Beyond these pedagogical concerns, there is the issue of bureaucracy associated with course administration that absorbs a significant amount of "non-teaching" time for any size class and is especially daunting for large classes that can exceed 350 students. Since most engineering courses require weekly homework submissions that are often 10-15 pages in length, the energy spent managing homework can consume an inordinate amount of time. Instructional staff can spend countless hours collecting assignments, deciphering hand-writing, etc. yet they find themselves unable to provide feedback individually since privacy concerns makes the job of returning weekly assignments next to impossible. When developing processes to return graded homework, faculty must also abide by the Family Educational Rights and Privacy Act (FERPA) and ensure that graded papers and/or exams are only shared directly with the student. In a class of 300+ students the logistics of returning homework directly to each student can be a time consuming task. In lower division classes over 50, teaching assistants and faculty often cannot positively ID most students by sight, which makes returning homework an even more daunting task. As discussed below, the content management system used in this study automated the collection and distribution of assignments and allowed for feedback at the individual level.

Flipping the Classroom

A key focus of this study is the effect of various online learning modalities as an adjunct to large (200-400) engineering courses which can be typical for sophomore and some junior level classes. 
The size of the class might not affect the delivery of the basic content, but it can have important effect on the learning side of the equation. Chances for distraction, losing concentration and train of thought are higher, while the opportunity for feedback to the instructor that some concepts are not absorbed is quite limited.

Augmenting their live lectures with some level of pre-recorded online content can be a partial solution to improving learning outcomes in these large classes. Faculty often begin this process by recording an exact replica of their live lectures (via various techniques described above) and make them available after the live lecture has been given. A portion of this study investigates the effect of posting pre-recorded lectures before the live lecture is given. This gives students more control of the learning process, which has been shown to increase the efficiency of learning ${ }^{1}$ and can allow faculty to utilize lecture time to include more student-faculty interactivity. There is much coverage of 'flipping the classroom' ${ }^{15,16}$ particularly in the context of the K-12 education, often in conjunction with online material from Kahn Academy or similar organizations.

The challenges faced in dealing with large enrollment engineering and other STEM classes are somewhat different. There the material is less generic and more tailor-made to the specific curriculum of the institution, often with variations to suit specific degrees and backgrounds. Unlike basic reading and arithmetic or similar topics, there is less research on best practices that help young adults grasp rather complex, often mathematically or scientifically oriented, material. As such, we often see a very large range of speed and comprehension even among students who are deemed to be similarly able (through the university admission process). Textbooks have been transformed from simple black/white texts with few simple figures into colorful productions, full of summary, key points, pictures and high quality drawings. Given the limited time of students for a given class, at times, this leads to a `sensory overload' of key material, which may or may not coincide with the instructor's point of view.

In a typical large class taught at research universities, the faculty member in charge of the course, due to experience and knowledge, gives the main lecture while teaching assistants deal with students in more one-on-one and smaller group discussion sessions ( although with larger classes even the discussion sections can be over 40 students). This is understandable given the costs associated with the process. The problem is that in many ways this is not the ideal mechanism of matching expertise. The most experienced person delivers rather standard lectures (close to the text and PowerPoints or lecture notes) with little interactions. The person to whom students can take their questions, frustrations and confusions is often far less experienced. It might be akin to having the physicians taking medical history and vital signs, while difficult diagnosis is referred to the nursing staff (or physician assistants). By far, the most expensive component of teaching is faculty time. T.A.'s are usually the second most costly resource since there are often as many as four required in larger class). One of the key initial motivations for this experiment was not to remove faculty from the student but to allow them to leverage their time and efforts at the most needed and critical stages of learning. 
A related aspect of this study was aimed at addressing these issues for the very large (300 plus) sophomore level Dynamics class. Along with online homework submission that was common to all three courses in this study, the sophomore class in Dynamics added the following features to the course shell to help address these issues:

- Pre-recorded Lectures - Short, 10-15 minute video lectures that cover the most difficult concepts are made accessible to the students via the course shell allowing students to control the speed and as-needed repeat any of the material -- at their own timing, subject to some global deadline. The questions and interactions regarding the most hard to grasp content is then addressed in the classroom with the main instructor.

- Quizzes - Quick (5 to 7 minute), low stakes quizzes that follow the video, to measure the students' grasp of the key concepts.

- Feedback Loop - The results from the quizzes were evaluated with adequate time for the instructor to consider the segments least understood and develop alternative coverage in the subsequent weeks live or video lectures to improve comprehension

Similar content was added to the Computer Aided Engineering course in the 2013 offerings.

Results

The results from the standard university evaluation form are shown in the table below. Students enter ratings on an A-F scale (including plusses and minuses) which are then converted to a numerical value with a range of 0.0 to 4.0. The column titled Outcomes is the students' response to the statement, "The course instructor meets stated objectives of the course." For all three courses the rating before and after the addition of various level of online content did not vary significantly. The way this question is worded may result in a measurement of both the course outcomes and students satisfaction with the instructor. The Instructor Rating and Course Rating columns are the students' responses to the questions, "What overall grade would you give this instructor?" and "What overall grade would you give the course?" In both cases there was little variation before and after the addition of online content except for the expected inverse variation of ratings versus class size. 


\begin{tabular}{|c|c|c|c|c|c|c|c|c|c|}
\hline Year & Course Title & $\begin{array}{l}\text { Class } \\
\text { Size }\end{array}$ & $\begin{array}{l}\text { Outcomes } \\
\text { Rating }\end{array}$ & 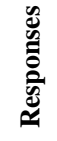 & $\begin{array}{c}\text { Instructor } \\
\text { Rating }\end{array}$ & 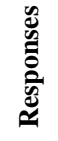 & $\begin{array}{l}\text { Course } \\
\text { Rating }\end{array}$ & 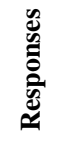 & Level of Hybridization \\
\hline 2011 & $\begin{array}{l}\text { Computer } \\
\text { Aided } \\
\text { Engineering }\end{array}$ & 42 & 3.86 & 17 & 3.84 & 17 & 3.79 & 17 & $\begin{array}{l}\text { Course Outline, Files and } \\
\text { Announcements }\end{array}$ \\
\hline 2012 & $\begin{array}{c}\text { Computer } \\
\text { Aided } \\
\text { Engineering } \\
\end{array}$ & 39 & 4.00 & 27 & 3.83 & 27 & 3.88 & 27 & $\begin{array}{l}+ \text { online homework } \\
\text { submission }\end{array}$ \\
\hline 2013 & $\begin{array}{l}\text { Computer } \\
\text { Aided } \\
\text { Engineering } \\
\end{array}$ & 80 & 3.8 & 72 & 3.7 & 72 & 3.6 & 72 & $\begin{array}{c}+ \text { online lectures, quizzes \& } \\
\text { polls }\end{array}$ \\
\hline 2011 & Dynamics & 314 & 3.7 & 295 & 3.5 & 295 & 3.4 & 295 & course outline only \\
\hline 2012 & Dynamics & 352 & 3.7 & 321 & 3.6 & 321 & 3.4 & 321 & $\begin{array}{c}+ \text { online homework } \\
\text { submission, lectures \& } \\
\text { quizzes } \\
\end{array}$ \\
\hline 2013 & Dynamics & 220 & 3.7 & 207 & 3.7 & 207 & 3.5 & 207 & $\begin{array}{c}\text { (class moved from } 50 \\
\text { minutes MWF to } 80 \text { minutes } \\
\mathrm{T} / \mathrm{Th} \text { ) }\end{array}$ \\
\hline
\end{tabular}

These ratings do not give the level of details required to formally assess the students' reactions and evaluation of the hybrid content. As a result, a second survey was designed to access the value of pre-recorded lectures and video versions of worked out homework. This survey was added as a required (but not graded) assessment within the online course shell for the 2012 Dynamics class and for all three classes for 2013.

A variety of questions were asked. In each, there were one to three options that would allow students to show their displeasure, disapproval, etc. Roughly two-thirds were highly supportive and depending on the question another $15-25 \%$ of the students were supportive. Consistently, between $5-8 \%$ of student considered the experiment either counter-productive or not worth the extra effort.

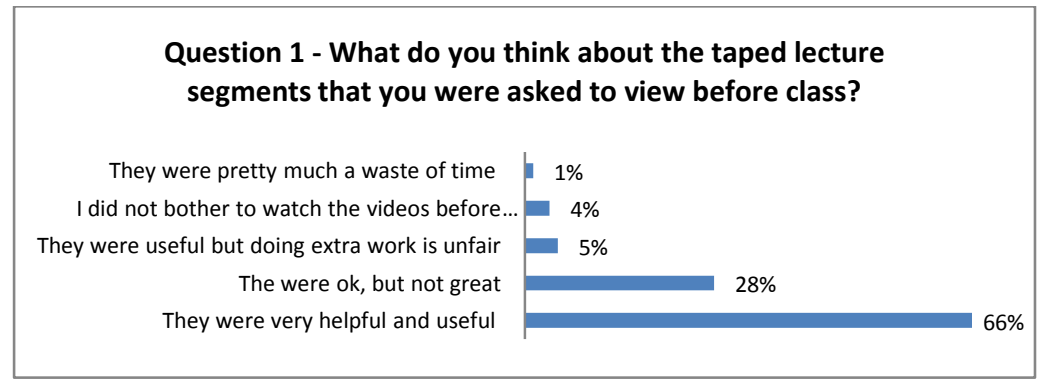

In the second question a majority of students indicated that having pre-recorded lectures helped them understand the course content better and found it useful that they could go back to the content at a later time. 


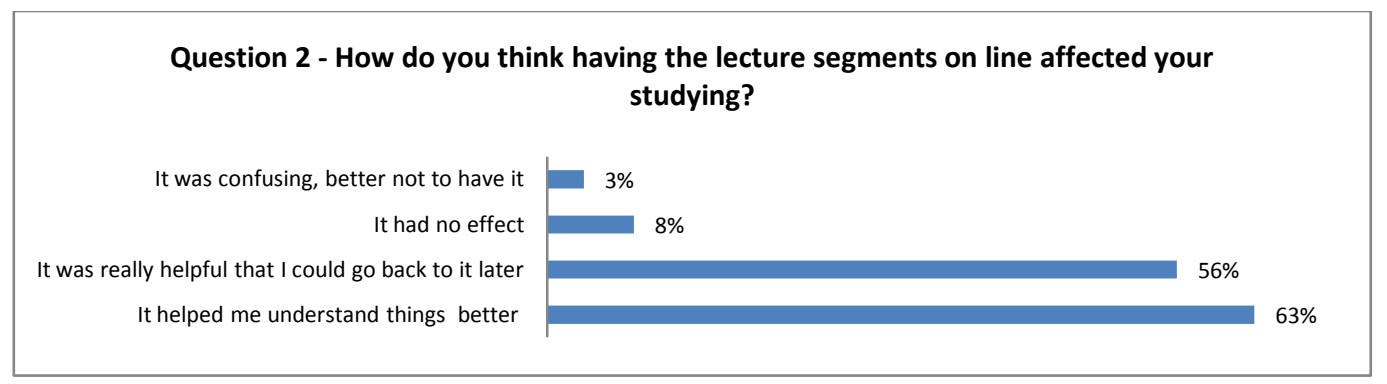

A majority of the students indicated that having prerecorded lectures would be helpful in more of their classes but it was interesting to note that $23 \%$ thought it was good for the current class (Dynamics) but not for other courses. In subsequent work, the authors plan to investigate the reason for this.

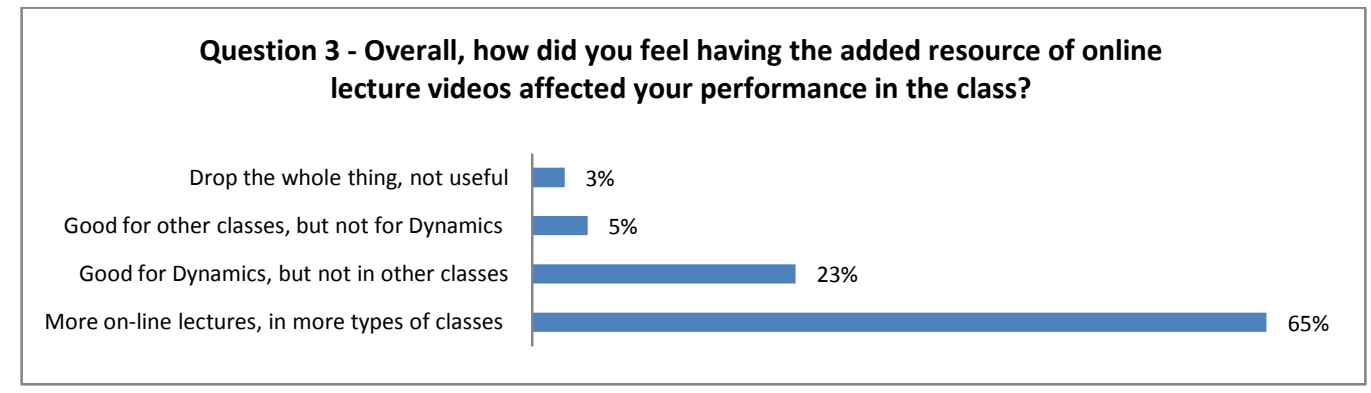

On the issue of attendance, the results were somewhat surprising. More than half claimed availability of many of the lectures has no effect on their attendance and about $10 \%$ claimed it made them more likely to go. About 35\% claimed that it made them less likely to go or select attendance based on the difficulty of the concepts.

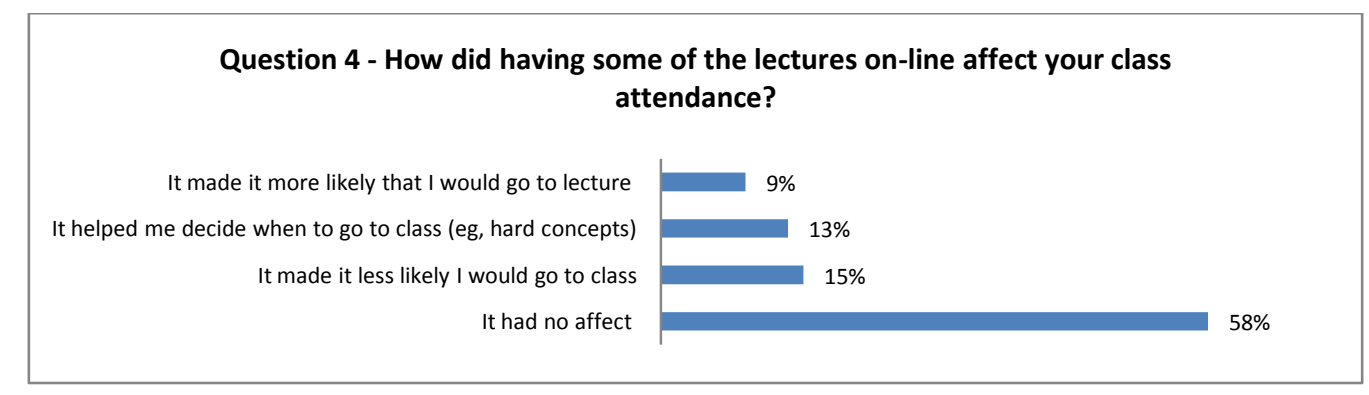

Similarly, in another question (with non-exclusive choice) half insisted on availability of regular lecture hours (review, asking questions) and about $40 \%$ marked the answer that self discipline would be a problem if all lectures were available on-line and attendance was not mandatory 


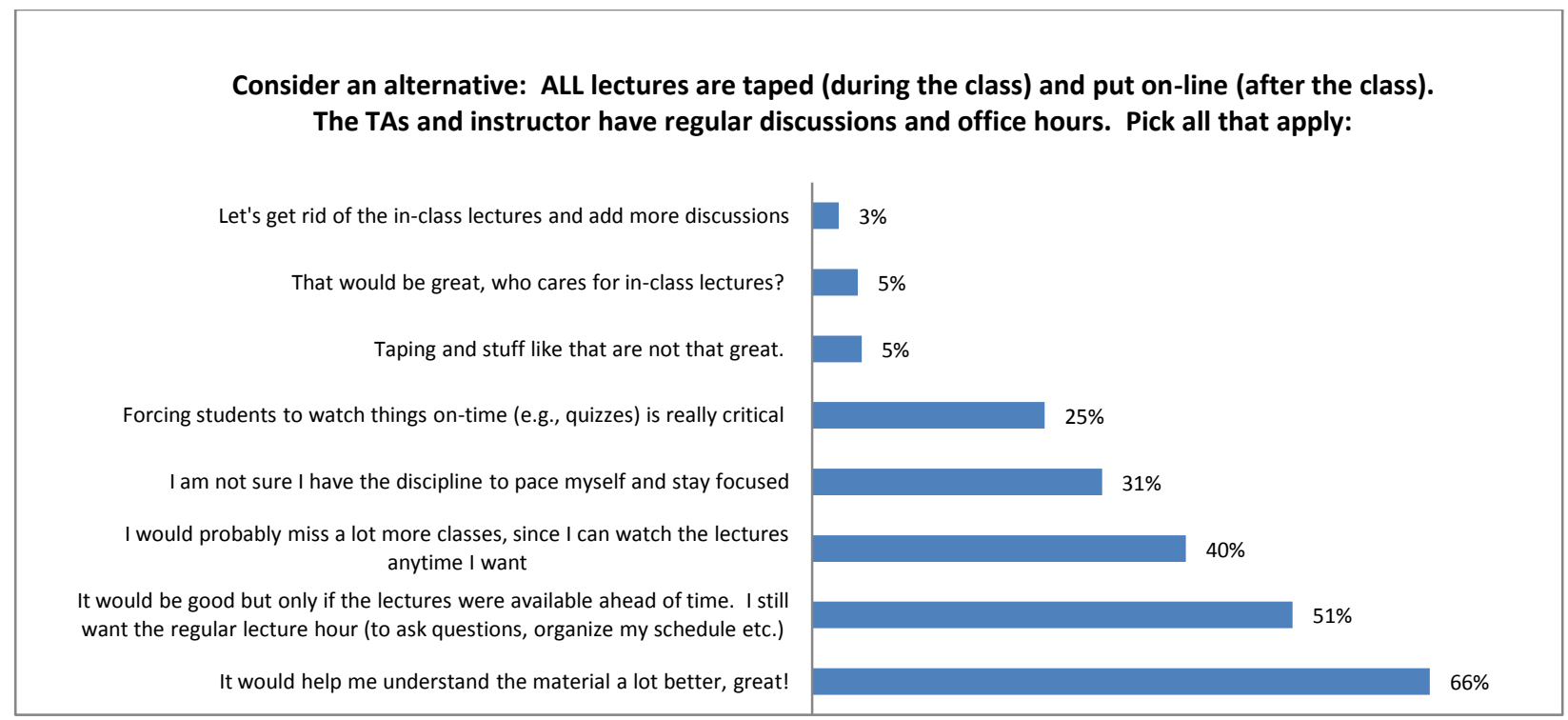

The last question in the survey was designed to evaluate the value of video versions of workedout homework (rather than just the written version typically posted after the homework due date has passed): $86 \%$ of the students said yes, although 50\% indicated that this was a good idea but only if the sessions where available for an extended period of time.

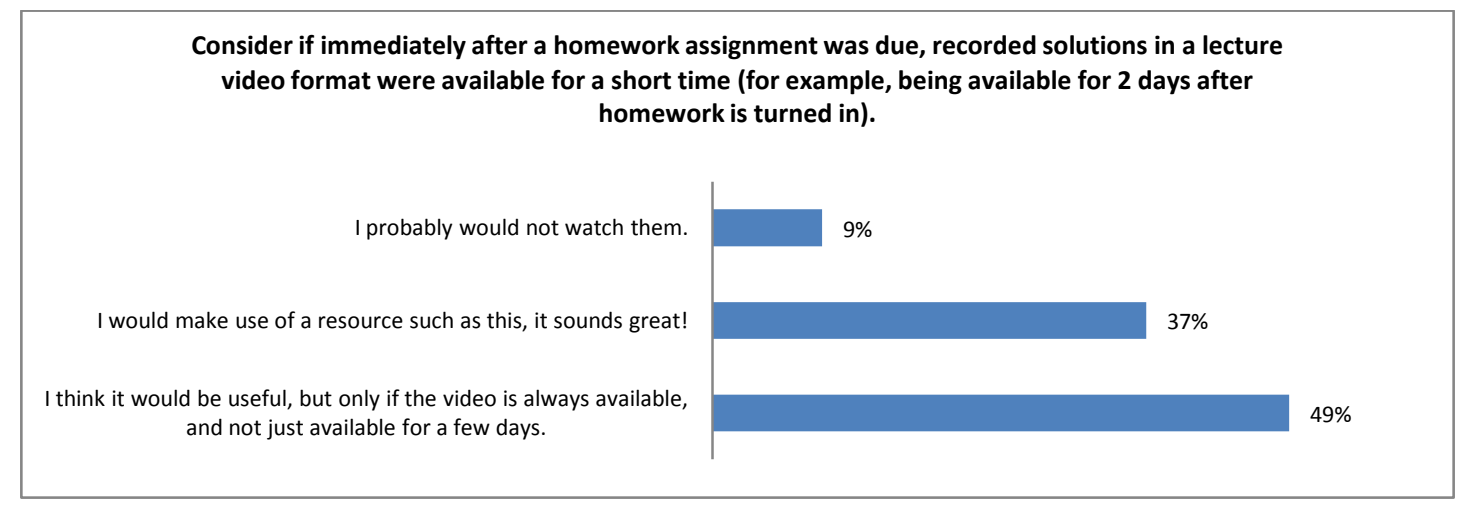

The material taught in the large class was identical each year. The summary PowerPoint slides (prepared for students who missed lectures) were used to ensure the same pace of coverage, same examples, same homework problems, and same concepts were covered. While the midterms were different (these exams are returned to students and have to be changed every year), the same final exam was given to students each year. The class sizes were similar (between 325 and 350). About $1 / 3$ of points were multiple choice questions. Two of the three people who graded the exams (with the same key) were common. The average grade in 2011 was 60.9, in 2012 it was 64.1 and in 2013 the average was 66.1. These results show a clear and positive impact $(8.4 \%$ increase in final exam scores) as the amount of online content was increased in this course. 


\begin{tabular}{|l|l|l|c|c|c|c|}
\hline \multicolumn{7}{|c|}{ Dynamics Course Final Exam Results } \\
\hline Year & $\begin{array}{l}\text { Class } \\
\text { Size }\end{array}$ & Responses & $\begin{array}{c}\text { Average } \\
\text { Grade } \\
\text { \% change } \\
\text { from baseline } \\
\text { year } \\
(2011)\end{array}$ & $\begin{array}{c}\text { Course } \\
\text { Rating }\end{array}$ & Notes \\
\hline 2011 & 314 & 318 & $\begin{array}{c}61.0 \\
(\sigma=15.4)\end{array}$ & - & 3.4 & $\begin{array}{c}\text { Course Outline, Files } \\
\text { and Announcements }\end{array}$ \\
\hline 2012 & 352 & 340 & $\begin{array}{c}64.1 \\
(\sigma=16.0)\end{array}$ & $+5.3 \%$ & 3.4 & $\begin{array}{c}\text { + online homework } \\
\text { submission, lectures \& } \\
\text { quizzes }\end{array}$ \\
\hline 2013 & 220 & 108 & $\begin{array}{c}66.1 \\
(\sigma=14.1)\end{array}$ & +8.4 & 3.5 & $\begin{array}{c}\text { Increased depth in the } \\
\text { modalities used in 2011 } \\
\text { and 2012 }\end{array}$ \\
\hline
\end{tabular}

\section{Operational Efficiencies}

Improving the efficient operation of classes can be a strong motivator for faculty to adopt online components to their classes. This is especially true for large classes which can often exceed 300 students.

During the second and third years of this study, faculty noticed a measurable reduction in time spent in administrative tasks especially as it related to submission and grading of homework. This was achieved by creating a simple file upload activity for each homework assignment within the MOODLE learning management system (LMS) replacing the "homework turn-in boxes" show below and more effectively deal with the related FERPA privacy issues.

Typical "Homework Turn-In" boxes for multiple undergraduate courses

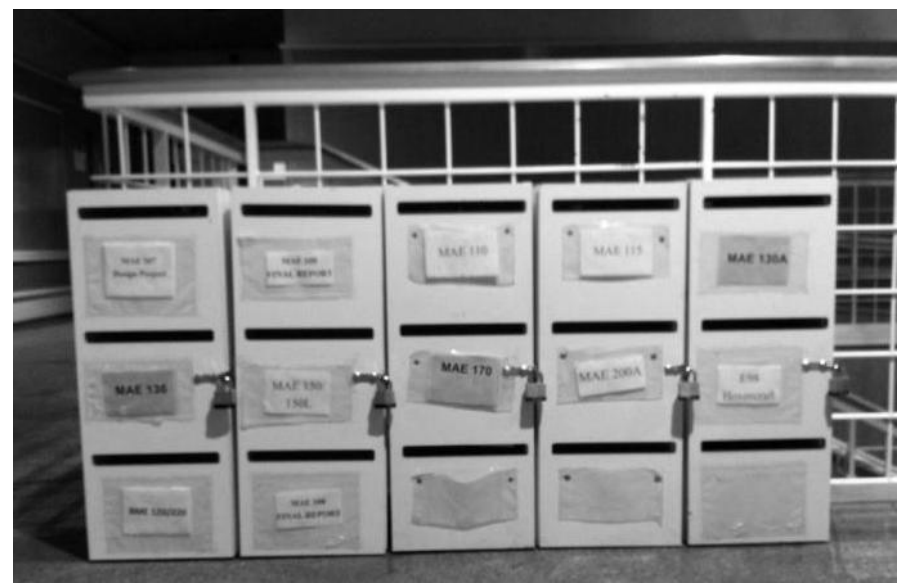


This system allows students to upload files in a variety of formats (Word, PDF and PowerPoint). This process is quite convenient for homework that can be completed using word processing software. However, in the past it had not been useful for a majority of homework assignments in engineering courses in which students must show calculations and diagrams related to each homework problem. To address this issue, in several of the courses that were part of this study students were asked to scan their written homework assignments and upload them to the Moodle course shell in PDF format. Students were notified of several locations on campus where they could utilize scanners. After the assignment due date, TA's and faculty would grade the homework and provide (mostly qualitative) feedback to the students which would be communicated to the student via e-mail and stored within the Moodle LMS system for future reference buy both students and faculty.

While this worked, students did report that finding and using a scanner to upload their homework was not very convenient. Students also tried to use their mobile phones to take pictures of each page of their homework for submission. Students reported that this was also difficult since mobile phone images are often $2 \mathrm{MB}$ or more per page and it was found that reducing the size (an option with most mobile phones when capturing and sending the image) reduced the image quality to a point that it was not useable to turn in homework. During the last year of the study (winter quarter 2013) students used free mobile phone applications such as the Genius Scan product (available for both iPhone and Android devices) that would allow students to capture images of their homework via their cell phone's camera but would enhance and reduce the size of the image. This processing which is most efficient for monochromatic images (e.g. most written engineering homework sets) took place on the cell phone prior to uploading the file. For most students this process still took two steps (1) capturing and sending the images to the student's email account and then (2) via the students computer, uploading those images to the course shell. The students also reported that the mobile application allowed them to connect several images together into a single file which made the process much more convenient than capturing each page as a separate image.

In this last year of the study both homework file upload activity and the mobile phone application were used to improve the operational efficiency of turning in homework. For each class taught using this process faculty and teaching assistants reported how much time was saved. The results: 


\begin{tabular}{|c|c|c|}
\hline \multicolumn{3}{|c|}{$\begin{array}{c}\text { Time Saved Using Online } \\
\text { Homework Submission } \\
(\mathrm{N}=\text { number of responses })\end{array}$} \\
\hline T.A. Time & $\mathrm{N}=12$ & $23 \%$ \\
\hline Faculty Time & $\mathrm{N}=6$ & $6 \%$ \\
\hline
\end{tabular}

Faculty saved an average of $6 \%$ and T.A.'s saved and average of $23 \%$ per class. In all the classes this time savings allowed both faculty and TA's to spend more time directly helping their students. In the larger classes with more than $4 \mathrm{TA}$ 's, faculty are considering reducing the number of TA's required for each course. When presented with this data, other faculty and academic administrators have expressed interest in adopting this process to improve the operational efficiency of a broader range of classes within the department.

\section{Summary}

This study investigated the integration of a range of hybrid course components aimed at improving outcomes, operational efficiency, student-faculty interaction, student feedback, efficiency of course administration and student "control" of course content within three engineering courses at a major U.S. research university. The results based on both subjective course evaluations and objective final exams scores, are consistent with previous research in which hybrid course student satisfaction levels and outcomes are rated equal to or better than $100 \%$ face-to-face classes. Efficiencies from the use of a single hybrid course component (online homework submission) resulted in less work for both T.A.'s and faculty allowing them to focus time on student interactions.

A parallel objective of this study was to utilize this evidence and other lessons learned to help develop a clear roadmap including a hybrid course maturity model to help motivate and guide other faculty at research universities to begin integrating online components into their courses and to help administration develop guidelines, process and resources to facilitate this practice. While further refinement of this is planned, the faculty involved in this study recommend:

For faculty:

- Begin with lower effort, attainable first step (integrate online homework submission, poll students, etc.)

- Identify campus instructional design and LMS tools experts

- Identify and consult with "early adopters" of hybrid technology within the department

- Utilize low cost student assistants to do repetitive tasks including transcribing lecture notes into PowerPoint or other formats that can be used to capture a lecture for posting to the course shell 
- Find a colleague in the department teaching courses in the same term that would be willing to collaborate in the integration of new hybrid course processes \& tools

- Focus on automating repetitive tasks (including lectures, homework turn-in, quizzes etc.) then focus on improving student interactions

- Incorporate best ideas and lessons learned into a course shell "template" that can be easily utilized in subsequent offerings of the class

For administration:

- Provide some workload release for instructors involved in the development of hybrid course components especially in the first year

- Invest in a variety (2-3) of relatively inexpensive tools to facilitate lecture capture including digital pens, tablets and portable document cameras (all under \$300) that can be made available at the department level and that give faculty a choice of which methods work best for their teaching style

- Adopt a common look and feel for hybrid courses

- Develop a standard course shell template that incorporates the lessons learned from previous hybrid classes within the department or school

- Create a short, simple guidebook (in print and online) that follows this template and provides assistance to faculty in the design and development of hybrid courses

- Create a small budget for student assistants who can be dedicated to repetitive tasks related to the development of hybrid course content

- Keep the same students in these positions for at least one year in an effort to draw a thread of continuity between courses and to leverage the students' expertise

- Market the benefits to the faculty (economic, outcomes, and student/instructor satisfaction)

A key component to the success of the process to improve course outcomes and operational efficiency during this study was that three courses were all taught in the same quarter and the faculty involved met 2-3 times during each quarter for 45-60 minutes to discuss techniques and tools that were working in each of the classes related to adjunct hybrid course content. During this time the instructors also met with and discussed course pedagogy and software tool utilization with instructional design and distance learning staff. This brainstorming and sharing of ideas by the faculty with guidance from experienced technical experts during the quarter in which the courses were taught accelerated the "iterative design process." This resulted in improved courses and the development of a path to continue this improvement in subsequent offerings and broaden the adoption of hybrid course content within the department and the school.

More study is required to further quantify these and related results for engineering and the broader category of STEM undergraduate courses. While capstone design classes do focus on the 
exploration of ideas, the application of theory and the "art" of engineering, a majority of courses taken by undergraduate STEM students continue to be focused on the dissemination of technical content. ${ }^{14}$ This latter category of instruction can benefit greatly in terms of student outcomes, efficiency, and student/faculty satisfaction, from the integration of hybrid courses design process and tools. While techniques like "flipping the classroom" have been adopted in some STEM disciplines (e.g., Physics), there is a need to investigate and quantify the effect of these changes in typical engineering courses. There is also a need to further quantify the optimal processes and tools when integrating hybrid components into face-to-face courses and or flipping all or part of a class. This is especially important for large classes which hinder interactions, student participation and instructor feedback. The authors look forward to refining this process to help motivate additional STEM faculty to adopt some level of hybridization of their courses and start them on a path of continuous optimization of learning outcomes and high efficiency delivery of both didactic content and design insight within undergraduate courses at research universities.

\section{Works Cited}

[1] B. Means, "Evalutaion of evidence-based practices in online learning: A meta-analysis and review of online learning studeis," U.S Department of Education, Washington D.C., 2010.

[2] E. N. Wiebe, T. J. Branoff and M. A. Shreve, "Online Resource Utilization in a Hybrid Course in Engineering Graphics," Advances in Engineering Education, pp. 1-21, 2011.

[3] M. K. Tallent-Runnels, "Teaching Courses Online: A review of the Research," Review of Educational Research Spring, vol. 76, no. 1, pp. 93-135, 2006.

[4] E. Lara and Victor Okhuysen, "Improving a traditional engineering lab thoguh conversion into a Hybrid course," in Proceedings of the 2012 ASEE PSW Section Conference, San Luis Obisbo, 2012.

[5] S. Riffella and D. Sibley, "Using web-based instruction to improve large undergraduate biology courses: An evaluation of a hybrid course format," Computers \& Education, pp. 217-235, 2005.

[6] K. L. Kasten, "Tenure and Merit Pay as Rewards for Research," The Journal of Higher Education, pp. Vol. 55, No. 4, 1984.

[7] B. L. Bower, "Distance Education:" Facing the Faculty Challeng"," Online Journal of Distance Learning Administration, vol. IV, no. II, 2001.

[8] C. D. Dziuban, P. D. Moskal and J. Hartman, "Higher education, blended learning, and the 
generations: Knowledge is power: No more.," in Elements of Quality Online Education, Needham, MA, Sloan, 2005.

[9] M. A. Ocak, "Why are faculty members not teaching blended courses ? Insights from faculty members," Computers \& Education, vol. 56, pp. 689-699, 2011.

[10] H. Sadaghiani, "Using multimedia Learning Modules in a Hybrid Online Course in Electricity and Magnetism," in American Physical Society, 2011.

[11] T. J. Branoff and K. Mapson, "Large Course redesign: Moving an Introductory Engineering GraphicsCourse from face-to-face to Hybrid Instruction," in ASEE Southeast Conference, 2009.

[12] R. J. Beck, "Teaching International Law as a Partially Online Course: The Hybrid/Blended Approach to Pedagogy.," International Studies Perspectives, vol. 11, no. 3, pp. 273-290, 2010.

[13] D. R. Garrison and H. Kanuka, "Blended learning: Uncovering its transformative potential in higher education," The Internet and Higher Education, vol. 7, no. 2, pp. 95-105, 2004.

[14] J. Bourne, D. Harris and F. Mayadas, "Online Engineering Education: Learning Anywhere, Anytime," Journal of Engineering Education, vol. 94, no. 1, pp. 131-146, 2005.

[15] J. Bergmann and A. Sams, "How the flipped classroom is radically transforming learning," 15 April 2012. [Online]. Available: www.thedailyriff.com/ articles/how-the-flipped-classroom-is-radicallytransforming-learning-536.php.. [Accessed 12 December 2012].

[16] C. Demetry, "Work in Progress - An Innovation Merging "Classroom Flip" and Team-Based Learning," in 40th ASEE/IEEE Frontiers in Education Conference, Washington, DC, 2010. 